\title{
ARTICLE
}

\section{Reactor radiation skyshine calculations with TRIPOLI-4 code for Baikal-1 experiments}

\author{
Yi-Kang Lee* \\ Commissariat à l'Energie Atomique et aux Energies Alternatives, CEA-Saclay, DEN/DANS/DM2S/SERMA, \\ 91191 Gif sur Yvette Cedex, France
}

\begin{abstract}
Neutron and photon fluxes generated from the operation of fission reactors and fuel cycle facilities are normally well attenuated with the shielding and ceiling walls. However, skyshine dose rates were observed at 1.5 - $2 \mathrm{~km}$ away from the JCO criticality accident site at Tokai-mura. In this study reactor neutron and photon skyshine calculations of Baikal-1 experiments have been performed with the TRIPOLI-4 Monte Carlo transport code. Baikal-1 experiments were carried out with the $300 \mathrm{~kW}$ RA research reactor. The $85 \mathrm{~cm}$ thick concrete shielding plug in the upper direction of the RA reactor was removed during the experiments. Various distances up to $1500 \mathrm{~m}$ from the reactor were considered for skyshine radiation measurements. To study the neutron and photon skyshine dose rates off the reactor with TRIPOLI-4 code, both photon and coupled neutron-photon calculations were performed so as to include primary photons, primary neutrons, and secondary photons contributions. TRIPOLI-4 perturbation calculations on the ground density and on the hydrogen concentration contained in the ground composition were also applied to study the groundshine.
\end{abstract}

Keywords: TRIPOLI-4; Monte Carlo; skyshine; reactor radiation; Baikal-1 experiments; benchmark; neutron dose; photon dose; variance reduction

\section{Introduction}

Radiation skyshine is one of the main subjects in radiation protection and shielding study. Neutron and photon fluxes generated from the operation of fission reactors and fuel cycle facilities are normally well attenuated with the shielding and ceiling walls [1]. Storage facilities of spent fuels, waste drums, and used components like steam generators [2], have also appropriate shielding to attenuate the neutron and/or photon skyshine dose. However, during the 1999 JCO criticality excursion accident at Tokai-mura, neutron and photon skyshine doses were observed and reported at 1.5 - $2 \mathrm{~km}$ away from the accident site, and furthermore, the measured skyshine radiation intensity followed the power excursion history [3].

The continuous-energy TRIPOLI-4 Monte Carlo transport code has been extensively applied on radiation shielding and reactor physics calculations [4]. In this study reactor neutron and photon skyshine calculations of Baikal-1 experiments have been performed in order to improve the TRIPOLI-4 code validation database.

Baikal-1 skyshine experiments were published in SINBAD-2005 and ICSBEP-2009 Handbooks [5]. The experiments were carried out with the RA research reactor. The $85 \mathrm{~cm}$ thick concrete shielding plug in the

*Corresponding author. Email: yi-kang.lee@cea.fr upper direction of the reactor was removed during the experiments to ensure the release of intensive fluxes of neutron and photon radiation to the air. Various distances up to $1500 \mathrm{~m}$ from the reactor were considered for skyshine measurements.

Both TRIPOLI-4 photon and coupled neutron-photon calculations were separately prepared to benchmark neutron and photon skyshine dose rates from the RA reactor. TRIPOLI-4 perturbation calculations on the material density and the concentration of nuclide were also applied to study the benchmark specifications and the groundshine.

\section{Baikal-1 skyshine experiments}

\subsection{Background of experiments}

The RA reactor is a part of the Baikal-1 complex of research reactors. It belongs to the Kurchatov Institute of Atomic Energy. Located in the Kazakhstan thinly populated steppe area, it was put into operation in 1987 and removed from operation in 1998. At the elevation of $290 \mathrm{~m}$ above sea level, the altitude variation in the region is very small. During 1996-1998, investigations of neutron and photon scattering in the atmosphere from the Baikal-1 reactors were performed. The skyshine measurement results depend highly on meteorological conditions. The chosen benchmark measurements from 
Baikal-1 experiments were conducted under air humidity of $33.9 \%$ and air temperature of $29.8{ }^{\circ} \mathrm{C}$ (Table 2.2, date 07/10/97 [5]).

\subsection{The $R A$ reactor building and biological shielding}

The RA reactor building was built on a foundation of $180 \mathrm{~cm}$ thick heavy concrete (see Figure 1). Lateral biological shielding was made of heavy serpentinite concrete with pig-iron fraction as a filler (density 3.27 $\mathrm{g} / \mathrm{cm}^{3}$ ). This shielding was arranged around the core and reflectors and was lined with a steel box-type structure. The lateral heavy concrete is $110-140 \mathrm{~cm}$ thick. It was surrounded with a steel bell-shaped structure about 35 $\mathrm{cm}$ thick. Inside the reactor hall, two ring-typed steel tanks of water were added. The radial thicknesses of these water rings were 34 and $90 \mathrm{~cm}$.

Above the reactor was a radiation shielding block consisting of a steel plate and a concrete plug with a thickness of $85 \mathrm{~cm}$. This block was removed during the experiments to release the RA reactor neutron and photon radiation to the sky air. Below the removable shielding block was the top steel cover of the reactor. The total thickness of this cover is $18 \mathrm{~cm}$ thick but with holes for the passage of air [5].

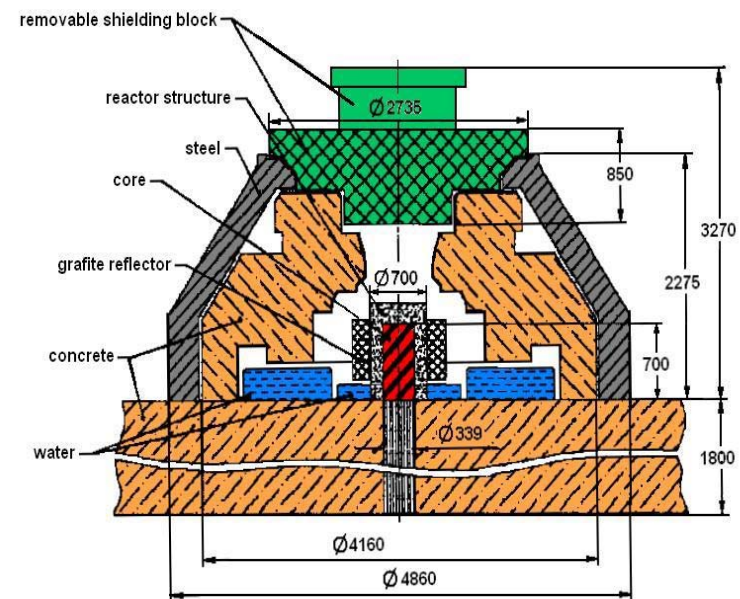

Figure 1. The RA reactor building and its biological shielding (dimension in $\mathrm{mm}$ ) [5] .

\subsection{The $R A$ reactor}

The core of the RA reactor was the source of the measured skyshine neutron and photon radiation. It was designed as a prototype of a space nuclear rocket engine. With a rating power of $300 \mathrm{~kW}$, the RA core was composed of 37 fuel elements in hexagonal lattice (see Figure 2, lattice with a pitch of $4.75 \mathrm{~cm}$ ). To reduce its dimension, 90\% enriched ${ }^{235} \mathrm{U}$ carbide fuel $\left(\mathrm{UC}_{2}\right)$ was used with a total ${ }^{235} \mathrm{U}$ mass of $8.1 \mathrm{~kg}$. $44.1 \mathrm{~kg} \mathrm{NbZr}$ was also used in the fuel zone to represent the cladding and structure materials. Zirconium hydride $\left(\mathrm{Zr}_{0.99} \mathrm{Nb}_{0.01}\right) \mathrm{H}_{1.8}$ was used as moderator and forced circulated air (3.3 $\mathrm{kg} / \mathrm{s}$ ) as coolant [5]. To improve the core neutronics performance, a lateral beryllium reflector was designed around the core with a thickness of $10.2 \mathrm{~cm} .12$ rotary boron carbide control elements were installed in the beryllium reflector. An additional lateral reflector/radiation shielding of graphite with $18 \mathrm{~cm}$ thickness was also added.

\subsection{Skyshine dose measurements}

Several measurements were performed for neutron and photon released to the atmosphere: (1) fast and thermal neutron fluxes and dose rates of neutron and photon at various altitudes above the reactor cover, (2) spatial distribution of neutron and photon dose rates away from the reactor, and (3) energy distribution of neutron and photon fluxes and dose rates at various distances from the reactor axis and from the reactor.

The measurements (1) and (3) were used by benchmark evaluators to estimate the "simplified" radiation source strength and spectra. The skyshine dose rates were measured $1 \mathrm{~m}$ above the ground level and measurement altitudes never exceeded $+/-5 \mathrm{~m}$. From the reactor axis, the radiation dose measurement distances from 100 to $1500 \mathrm{~m}$ were reported.

Neutron dose was measured with scintillation counter under polyethylene spheres and photon dose with tissue-equivalent scintillator and TLD dosimeters. According to the ICSBEP document [5], the uncertainty of the reactor power is $7 \%$ and the maximal uncertainty of integral measurements can be estimated as much as $14 \%$ above the reactor and $17 \%$ for the skyshine on-site measurements.

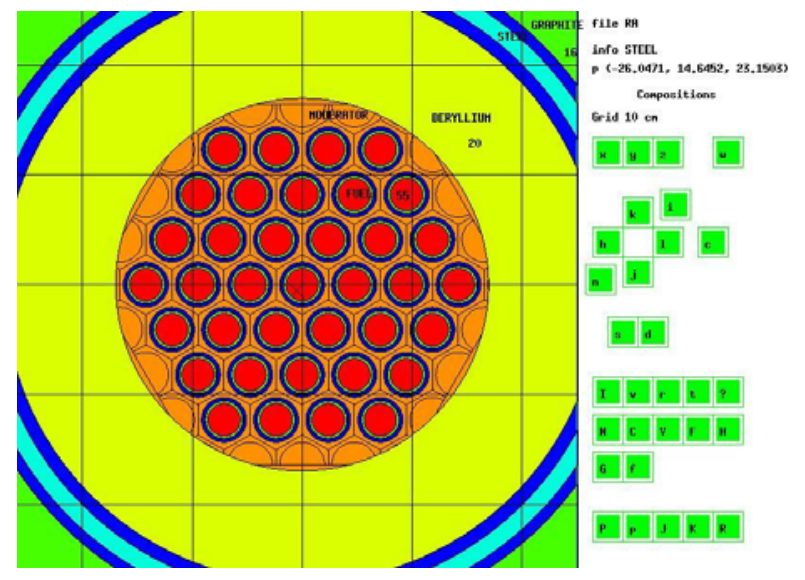

Figure 2. TRIPOLI-4 modeling of the RA reactor (Core, radial reflectors in beryllium, and graphite).

\section{TRIPOLI-4 calculations}

\subsection{TRIPOLI-4 calculation methods}

TRIPOLI-4 was first run with the criticality mode to study the fission neutron source of the RA core. Due to the fact that the positions of 12 rotary control elements in beryllium are not available, the Keff values and the power map of RA core depend on the control element modeling (Fig. 1.5 [5]). 
To benchmark with the leaking neutron and photon responses from the RA reactor cover, the shielding mode of TRIPOLI-4 was secondly applied by using the calculated neutron source distribution. Due to the homogenization of radiation shielding layers in the upper direction of the RA reactor, a divergence of the calculation results and experimental data has been obtained. This divergence of results can also be found from the Tables 3.2 to 3.4 of reference [5].

To perform the shielding calculations with TRIPOLI-4, the variance reduction technique INIPOND has been applied in order to push the radiation to the upper direction of the RA reactor hall [4]. TRIPOLI-4 display tools for collision sites and iso-importance curves have been also used [6].

To study the skyshine radiation at various distances away from the RA reactor, both photon and coupled neutron-photon calculations were necessary. To improve the calculation performance, two other variance reduction techniques were applied. The first is to increase the photon production yield by using the photon-neutron ratio option [4]. This option performs the splitting of secondary photons and improves the photon dose estimation. The second is the ring tally. The point detector is available in TRIPOLI-4 code but the ring detector is not. To overcome this limit, the ring tally (Figure 3) was applied by using the ring volume cells and the ring mesh tallies.

To evaluate the skyshine dose rates from the calculated neutron and photon flux in the ring tally, the ICRP-74 flux-to-dose rate conversion factors, which are available in TRIPOLI-4 code, were applied.

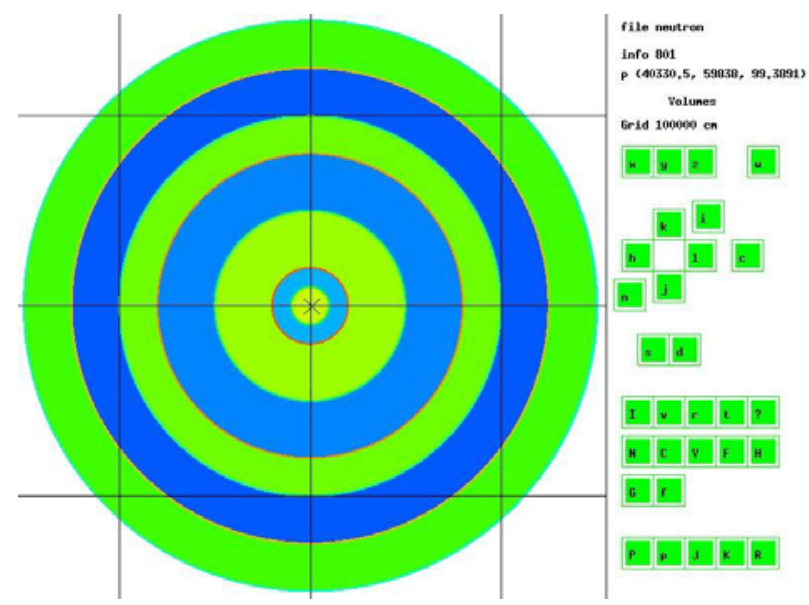

Figure 3. TRIPOLI-4 modeling of ring-tally for skyshine calculations (up to $1500 \mathrm{~m}$ off the RA reactor).

\subsection{TRIPOLI-4 modeling of Baikal-1 experiments}

Two benchmark models were proposed by the benchmark evaluators to calculate the neutron and photon skyshine radiation fields: a "simplified" model with an effective point source of radiation and an "accurate" model which has detailed modeling of the geometry and material structures of the experiments.
When checking the RA reactor core and the reactor hall data, the dimension and material data are not fully described in the benchmark document. According to the evaluators of the benchmark, an additional uncertainty of $6 \%$ is assigned to the expected on-site results from the "point source" model due to a model simplification (p.59 [5]). Instead of using unclear data for the "accurate model", it is decided in this study to use the "point source" model directly in the skyshine TRIPOLI-4 calculations.

The effective point source releases radiation directly within a cone. The cone opening half-angle is $38^{\circ}$. The energy distributions are also provided in the Table 2.4 of reference [5]. The evaluated source intensities, corresponding to the reactor power $300 \mathrm{~kW}$, within the cone are, respectively, 2.0E14 n/s and 5.1E14 $\gamma / \mathrm{s}$. The angular distribution is uniform from the point source within the cone. The point source is located at the upper surface of the $30 \mathrm{~cm}$ thick ground.

A four-layer air model [5] has been applied in the TRIPOLI-4 calculations (from the ground level, $100 \mathrm{~m}+$ $100 m+200 m+800 m$ with the air density changing with height). The ring tally, placed on $1 \mathrm{~m}$ above the ground level, has a height of $10 \mathrm{~cm}$ and a thickness of 10 $\mathrm{m}$.

\subsection{TRIPOLI-4 skyshine dose rates results}

Table 1 shows the measured and TRIPOLI-4 calculated neutron skyshine dose rates from the RA reactor. Satisfactory agreement has been obtained when including the experimental uncertainties.

Table 1. Neutron skyshine dose rates from the RA reactor (Normalized to the reactor power $300 \mathrm{~kW}$ ).

\begin{tabular}{|c|c|c|c|}
\hline $\begin{array}{l}\text { Distance } \\
\text { from the } \\
\text { Reactor (m) }\end{array}$ & $\begin{array}{l}\text { Measurement + } \\
07 / 10 / 97 \\
(\mu \mathrm{Sv} / \mathrm{h})(\sigma \%)\end{array}$ & $\begin{array}{l}\text { TRIPOLI-4 } \\
\text { Calculations } \\
(\mu \mathrm{Sv} / \mathrm{h})(\sigma \%)\end{array}$ & $\mathrm{C} / \mathrm{M}$ \\
\hline 100 & $1.11 \mathrm{E} 5 \quad(3.5)$ & $\begin{array}{ll}9.85 \mathrm{E} 4 & (0.1)\end{array}$ & 0.89 \\
\hline 200 & $2.41 \mathrm{E} 4 \quad$ (3.9) & $2.16 \mathrm{E} 4 \quad(0.1)$ & 0.90 \\
\hline 500 & 8.52E2 (5.6) & $9.32 \mathrm{E} 2 \quad(0.1)$ & 1.09 \\
\hline 800 & 6.17E1 (7.1) & $7.28 \mathrm{E} 1 \quad(0.3)$ & 1.18 \\
\hline 1000 & $1.22 \mathrm{E} 1 \quad(7.6)$ & $1.53 \mathrm{E} 1 \quad(0.7)$ & 1.25 \\
\hline 1250 & 2.01E0 (9.1) & 2.45E0 (1.5) & 1.22 \\
\hline 1500 & $3.80 \mathrm{E}-1 \quad(9.8)$ & $4.46 \mathrm{E}-1 \quad(3.6)$ & 1.17 \\
\hline
\end{tabular}

+ Table 1.12 of reference [5].

Table 2 shows the measured and TRIPOLI-4 calculated photon skyshine dose rates from the RA reactor. At the same measurement sites, the photon skyshine dose rates are always smaller than neutron skyshine ones (cf. Table 1). Using the photon skyshine benchmark data, C/M values are from 0.39 to 0.71 .

To clarify the $\mathrm{C} / \mathrm{M}$ values in Table 2, several TRIPOLI-4 perturbation calculations have been applied on the cell density and the concentration of nuclide. The most important impact is from the hydrogen contained in the ground composition. When it decreases by $10 \%$, the skyshine neutron dose rates increase a few percent but 
the photon dose rates increase by $20 \%(>1000 \mathrm{~m})$ to $40 \%(<800 \mathrm{~m})$.

Table 2. Photon skyshine dose rates from the RA reactor (Normalized to the reactor power $300 \mathrm{~kW}$ ).

\begin{tabular}{|c|c|c|c|}
\hline $\begin{array}{l}\text { Distance } \\
\text { from the } \\
\text { Reactor (m) } \\
\end{array}$ & $\begin{array}{l}\text { Measurement + } \\
07 / 10 / 97 @ \\
(\mu \mathrm{Sv} / \mathrm{h})(\sigma \%) \\
\end{array}$ & $\begin{array}{l}\text { TRIPOLI-4 } \\
\text { Calculations } \\
(\mu \mathrm{Sv} / \mathrm{h})(\sigma \%) \\
\end{array}$ & $\mathrm{C} / \mathrm{M}$ \\
\hline 100 & 5.22E3 (4.0) & $2.04 \mathrm{E} 3 \quad(0.1)$ & 0.39 \\
\hline 200 & $1.04 \mathrm{E} 3 \quad(4.5)$ & $4.68 \mathrm{E} 2 \quad(0.1)$ & 0.45 \\
\hline 500 & 4.60E1 (4.5) & $2.40 \mathrm{E} 1 \quad(0.2)$ & 0.52 \\
\hline 800 & 5.43E0 (8.5) & 2.97E0 (0.6) & 0.55 \\
\hline 1000 & 1.46E0 (9.2) & $9.78 \mathrm{E}-1 \quad(0.8)$ & 0.67 \\
\hline 1250 & 6.70E-1 (10.5) & $2.84 \mathrm{E}-1$ & 0.42 \\
\hline 1500 & $1.40 \mathrm{E}-1(12.0)$ & $9.98 \mathrm{E}-2 \quad(1.7)$ & 0.71 \\
\hline
\end{tabular}

Table 3 shows the photon skyshine benchmark between TRIPOLI-4 (T4) and MCNP5 (M5) calculations. Different air models, flux-to-dose rate conversion factors and cross-section data libraries have been used with these two codes and less than 20\% difference has been found.

Using both ICRP-74 and ICRP-21 flux-to-dose rate conversion factors in previous study [7], higher photon dose rates were obtained with ICRP-74 conversion factors. The increase of $14 \%$ in photon dose rates by using ICRP-74 conversion factors in reference 7 is useful to explain the T4/M5 ratios of Table 3. In fact, the ICRP-74 conversion factors are also helpful to improve the $\mathrm{C} / \mathrm{M}$ ratios in this study.

Table 3. Photon skyshine dose rates from the RA reactor (Normalized to the reactor power $300 \mathrm{~kW}$ ).

\begin{tabular}{|c|c|c|c|}
\hline $\begin{array}{l}\text { Distance } \\
\text { from the } \\
\text { Reactor (m) }\end{array}$ & $\begin{array}{l}\text { MCNP5 * } \\
(\mathrm{ICRP}-21) \\
(\mu \mathrm{Sv} / \mathrm{h})(\sigma \%)\end{array}$ & $\begin{array}{l}\text { TRIPOLI-4 } \\
(\mathrm{ICRP}-74) \\
(\mu \mathrm{Sv} / \mathrm{h})(\sigma \%)\end{array}$ & T4/M5 \\
\hline 100 & $1.71 \mathrm{E} 3 \quad(0.2)$ & $\begin{array}{ll}2.04 \mathrm{E} 3 & (0.1)\end{array}$ & 1.19 \\
\hline 200 & $4.02 \mathrm{E} 2 \quad(0.3)$ & 4.68E2 (0.1) & 1.16 \\
\hline 500 & $2.12 \mathrm{E} 1 \quad(0.9)$ & $2.40 \mathrm{E} 1 \quad(0.2)$ & 1.13 \\
\hline 800 & $2.67 \mathrm{E} 0 \quad(2.2)$ & 2.97E0 (0.6) & 1.11 \\
\hline 1000 & 8.23E-1 (3.7) & $9.78 \mathrm{E}-1 \quad(0.8)$ & 1.19 \\
\hline 1250 & n.a. & $2.84 \mathrm{E}-1 \quad$ (1.1) & \\
\hline 1500 & $\mathrm{n}, \mathrm{a}$ & $9.98 \mathrm{E}-2 \quad(1.7)$ & \\
\hline
\end{tabular}

* Table 4.7 [5], uniform air density 1.135E-3 g/ $\mathrm{cm}^{3}$.

Table 4 shows the detailed TRIPOLI-4 calculated photon skyshine dose rates from the RA reactor. The primary photon skyshine from the RA reactor decreases in a relatively rapid way with the distance from the reactor. The main contribution of photon skyshine at 800 - $1500 \mathrm{~m}$ off the RA reactor is from the secondary photons generated from the coupled neutron-photon calculations. Depending on the meteorological conditions, the ground formation, and the soil surface plants, the dose rates from secondary photons changed.
Table 4. Photon skyshine dose rates from the RA reactor (Normalized to the reactor power $300 \mathrm{~kW}$ ).

\begin{tabular}{|c|c|c|c|}
\hline $\begin{array}{l}\text { Distance } \\
\text { from the } \\
\text { Reactor (m) }\end{array}$ & $\begin{array}{l}\text { TRIPOLI-4 } \\
2^{\text {nd }} \text { gamma } \\
(\mu \mathrm{Sv} / \mathrm{h})(\sigma \%)\end{array}$ & $\begin{array}{l}\text { TRIPOLI-4 } \\
\text { RA gamma } \\
(\mu \mathrm{Sv} / \mathrm{h})(\sigma \%)\end{array}$ & $(\mu \mathrm{Sv} / \mathrm{h})$ \\
\hline 100 & $1.06 \mathrm{E} 3 \quad(0.1)$ & $9.74 \mathrm{E} 2 \quad(0.1)$ & $2.04 \mathrm{E} 3$ \\
\hline 200 & 2.63E2 (0.1) & $2.05 \mathrm{E} 2 \quad(0.1)$ & $4.68 \mathrm{E} 2$ \\
\hline 500 & $1.81 \mathrm{E} 1 \quad(0.2)$ & 5.93E0 (0.2) & $2.40 \mathrm{E} 1$ \\
\hline 800 & $2.66 \mathrm{E} 0 \quad(0.4)$ & $3.06 \mathrm{E}-1 \quad(0.8)$ & 2.97E0 \\
\hline 1000 & $9.26 \mathrm{E}-1 \quad(0.7)$ & $5.16 \mathrm{E}-2 \quad(1.6)$ & 0.978 \\
\hline 1250 & $2.84 \mathrm{E}-1 \quad$ (1.1) & n.a. & 0.284 \\
\hline 1500 & $9.98 \mathrm{E}-2 \quad(1.7)$ & n.a. & 0.100 \\
\hline
\end{tabular}

\section{Conclusion}

In this study, TRIPOLI-4 capabilities on reactor radiation skyshine calculations have been demonstrated. The perturbation options of the code are useful to verify the benchmark specifications for the radiation skyshine and groundshine calculations. The reactor radiation skyshine dose rates depend highly on meteorological conditions and ground formation. The neutron skyshine dose rates are always dominant. Effect of soil surface plants and soil moisture are also important. They are taken into account in the measurements of skyshine dose rates and they must be considered in the calculation models. Future study to improve the modeling of RA reactor shielding and reactor hall will be helpful for benchmark calculations of neutron and photon doses at various altitudes above the reactor cover.

\section{Acknowledgements}

The author acknowledges the EDF and AREVA support.

\section{References}

[1] J. K. Shultis and R. E. Faw, Radiation Shielding, American Nuclear Society, Illinois, (2000), ISBN 0-89448-456-7.

[2] Y. K. Lee, J. C. Nimal and P. Ridoux, Gamma-ray skyshine analysis with TRIPOLI Monte Carlo code, Proc. ANS Topical Meeting on Radiation Protection and Shielding, No. Falmouth, MA, USA, April 21-25, 1996, (1996), p. 809.

[3] A. Endo, Dose assessment in the criticality accident at Tokai-mura, Radiation Measurements 45 (2010), pp. 1484-1490.

[4] O. Petit, F. X. Hugot, Y. K. Lee and C. Jouanne, TRIPOLI-4 Version 4 User Guide, CEA-R-6169, (2008). http://www.nea.fr/abs/html/nea-1716.

[5] O. F. Dikareva, I. A. Kartashev, M. E. Netecha and V. P. Zharkov, Baikal-1 Skyshine Experiment, NEA/NSC/DOC/(95)03/VIII, ALARM-REACAIR-SKY-1, Sep. 30, 2009, revision 1, NEAICSBEP Database.

[6] F. X. Hugot and Y. K. Lee, A new display tool for the Monte Carlo particle transport code TRIPOLI-4, Progress in Nuclear Science and Technology Vol. 
2, (2011), pp. 851-854.

[7] Y. K. Lee and K. Sharma, TRIPOLI-4 gamma-ray dose calculation for spent PWR fuels, Proc. ASME
2013 21th Int. Conf. on Nuclear Engineering (ICONE21-15498), Chengdu, China, July 29 August 2, 2013, (2013). [CD-ROM] 